\title{
KORELASI UKURAN KETEBALAN KORTEKS DAN RESISTIVE INDEX GINJAL BERDASARKAN PEMERIKSAAN ULTRASONOGRAFI PADA PASIEN HIDRONEFROSIS
}

\section{THE CORRELATION BETWEEN THE SIZE OF CORTEX THICKNESS AND THE RESISTIVE INDEX OF KIDNEY BASED ON ULTRASONOGRAPHY EXAMINATION IN HYDRONEPHROSIS PATIENTS}

\author{
Ferawati Dakio $^{1 *}$, Nurlaily Idris ${ }^{1}$, Mirna Muis ${ }^{1}$, Andi Alfian², Hasyim Kasim ${ }^{3}$, Bachtiar \\ Murtala ${ }^{1}$ \\ ${ }^{I}$ Departemen Radiologi, Fakultas Kedokteran, Universitas Hasanuddin, \\ Jalan Perintis Kemerdekaan Km.10 Makassar, Sulawesi Selatan, Indonesia \\ ${ }^{2}$ Departemen Ilmu Kesehatan Masyarakat/Ilmu Kedokteran Keluarga, Fakultas Kedokteran, Universitas \\ Hasanudin, \\ Jalan Perintis Kemerdekaan Km.10 Makassar, Sulawesi Selatan, Indonesia \\ ${ }^{3}$ Departemen Ilmu Penyakit Dalam, Fakultas Kedokteran, Universitas Hasanudin, \\ Jalan Perintis Kemerdekaan Km.10 Makassar, Sulawesi Selatan, Indonesia
}

\begin{abstract}
ABSTRAK
Hidronefrosis merupakan kelainan pada aliran urin menjadi lemah yang dapat terjadi pada satu atau kedua ginjal, sehingga dapat mengganggu fungsi ginjal. Penelitian ini bertujuan untuk mengetahui korelasi ketebalan korteks ginjal dan resistive index ginjal berdasarkan pemeriksaan ultrasonografi pada pasien hidronefrosis. Penelitian ini dilakukan di Bagian Radiologi Rumah Sakit Umum Pusat Dr. Wahidin Sudirohusodo Makassar pada bulan MeiAgustus 2018. Desain penelitian yang digunakan yaitu observasional dengan rancangan potong lintang. Sampel penelitian sebanyak empat puluh orang yang memiliki klinis hidronefrosis. Pemeriksaan ultrasonografi grayscale terhadap pasien dilakukan untuk mengukur ketebalan korteks ginjal yang dilakukan di bagian tengah ginjal pada potongan longitudinal dan diukur dari puncak piramid tegak lurus ke arah kapsul. Pemeriksaan ultrasonografi doppler di arteri interlobar atau arcuata pada pole superior, median, dan inferior ginjal untuk menilai renal resistive index. Analisis data statistik yang digunakan adalah uji korelasi Spearman dan Pearson. Hasil penelitian menunjukkan bahwa rerata sampel penelitian mengalami hidronefrosis derajat ringan. Rerata tebal korteks ginjal kanan pada penelitian ini $0,9 \mathrm{~cm}$ dengan rentang $0,26-1,79 \mathrm{~cm}$ dan ginjal kiri $0,84 \mathrm{~cm}$ dengan rentang $0,22-1,57 \mathrm{~cm}$. Terdapat korelasi yang bermakna antara derajat hidronefrosis dengan ketebalan korteks ginjal kanan dan kiri dengan arah korelasi negatif $(\mathrm{p}=0,0001)$. Kecenderungan peningkatan derajat hidronefrosis, meningkatkan nilai resistive index meskipun secara statistik tidak bermakna. Namun, tidak terdapat korelasi antara ketebalan korteks dan resistive index ginjal berdasarkan pemeriksaan ultrasonografi.
\end{abstract}

Kata kunci : hidronefrosis, ketebalan korteks ginjal, resistive index ginjal, ultrasonografi doppler 


\begin{abstract}
Hydronephrosis can occur in one or both kidneys which cause the flow of urine to become weak and interfere with the function of the kidney. This research aimed to investigate the correlation between the cortex thickness and the resistive index of kidney based on the ultrasonography examination in hydronephrosis patients. The research was conducted in Radiology Department of Dr. Wahidin Sudirohusodo General Hospital, Makassar from May through August 2018. The research design used was observational using the cross sectional design. The total samples comprised 40 samples with clinical hydronephrosis. The examination of ultrasonography grayscale was carried out to measure the cortex thickness of the kidneys in the central parts of kidneys and the longitudinal cut was measured from the pyramid top straight down the capsule, then it was continued with the Doppler ultrasonography examination in the interlobare artery or arcute at superior pole, median and inferior kidney to evaluate the renal resistive index. The data were analyzed using the statistical analysis through the correlation tests of Spearman and Pearson. The research results indicated that the mean research samples had experienced light hydronephrosis. The mean cortex thickness of the right kidney was $0.9 \mathrm{~cm}$ $(0.26-1.79 \mathrm{~cm})$, and that of the left kidney was $0.84 \mathrm{~cm}(0.22-1.57 \mathrm{~cm})$. There was a significant correlation between the degree of hydronephrosis and the cortex thickness of the right and the left kidneys, with the direction of the negative correlation $(p=0.0001)$. There was a tendency of the increase of hydronephrosis degree to increase the value of a resistive index, though statistically, it was insignificant. There was no correlation between the cortex thickness and the resistive index of kidney based on the ultrasonogrphy examination.

Keywords: doppler ultrasonography, hydronephrosis, resistive index of kidney, thickness of cortex kidney
\end{abstract}

\title{
Penulis korespondensi:
}

Ferawati Dakio

Departemen Radiologi, Fakultas Kedokteran, Universitas Hasanuddin

Jl.Perintis Kemerdekaan Km. 10, Makassar

Email :dakio.ferawati@gmail.com

\section{PENDAHULUAN}

Hidronefrosis merupakan suatu kondisi klinis umum yang didefinisikan sebagai distensi dari calyces ginjal dan pelvis oleh urin akibat obstruksi aliran keluar urin ke distal dari pelvis renalis. Hidronefrosis bisa terjadi pada satu atau kedua ginjal yang menyebabkan aliran urin menjadi lemah dan mengganggu fungsi ginjal. Hidronefrosis dapat bersifat fisiologis atau patologis, akut atau kronis, dan unilateral ataupun bilateral. Hidronefrosis dapat menjadi sekunder disebabkan adanya obstruksi saluran kemih, tetapi juga dapat terjadi bahkan tanpa obstruksi (Esprit et al., 2017).

Uropati obstruktif mengacu pada obstruksi fungsional atau anatomi aliran kemih pada setiap tingkat saluran kemih. Nefropati obstruktif terjadi ketika obstruksi menyebabkan kerusakan ginjal fungsional atau anatomi. Nefropati obstruktif jarang terjadi tanpa adanya 
hidronefrosis. Dengan demikian, istilah hidronefrosis dan obstruksi tidak boleh digunakan secara bergantian (Esprit et al., 2017).

Etiologi hidronefrosis pada orang dewasa berbeda dengan neonatus yang terjadi pada anak-anak. Kelainan anatomi (termasuk katup uretra atau struktur dan stenosis pada ureterovesikal atau ureteropelvic junction) merupakan penyebab mayoritas kasus pada anakanak. Perbedan yang terjadi, calculi paling umum pada dewasa muda, sedangkan pada pasien yang lebih tua paling utama disebabkan karena adanya hipertrofi prostat atau karsinoma, retroperitoneal atau neoplasma dan batu (Lameire et al., 2015).

Gejala klinis hidronefrosis tergantung dari penyebabnya. Kasus hidronefrosis semakin sering ditemukan pada beberapa negara misalnya Amerika Serikat. Insidensi hidronefrosis di Amerika Serikat, mencapai 3,1\%. Sebanyak 2,9\% terjadi pada wanita dan 3,3\% pada pria. Obstruksi merupakan penyebab utama terjadinya hidronefrosis dengan keluhan pasien yang dipengaruhi oleh banyak factor. Faktor-faktor yang mempengaruhi antara lain yaitu interval sejak mulai obstruksi sampai berobat (akut atau kronik), adanya infeksi, penyebab obstruksi (intrinsik/ekstrinsik), unilateral atau bilateral, derajat obstruksi parsial atau total (Singh et al., 2012; Sukmagara dan Danarto, 2015).

Obstruksi dapat bersifat reversible dan irreversible. Saat ini belum ada guideline atau konsensus parameter prognostik yang dapat menjelaskan sifat yang terjadi. Diagnosis obstruksi dapat diperiksa secara langsung dan tidak langsung. Pemeriksaan secara langsung dapat dilakukan dengan pemeriksaan biopsi ginjal dan radiologi. Pemeriksaan tidak langsung yaitu dengan pemeriksaan urinalisis. Modalitas radiologi yang dapat digunakan diantaranya adalah ultrasonografi (USG), computed tomography (CT), magnetic resonance imaging (MRI) dan renogram. Pemeriksaan gold standard dengan renogram namun pemeriksaan renografi masih belum dapat dilakukan secara rutin karena biaya yang tinggi, keterbatasan alat dan bersifat invasif (Singh et al., 2012).

Pemeriksaan USG merupakan salah satu modalitas radiologi yang sering digunakan untuk evaluasi awal penyumbatan ginjal dalam berbagai kondisi pada pasien hidronefrosis. Pemeriksaan USG memiliki beberapa kelebihan seperti pemeriksaan yang cepat, tidak invasif untuk mengevaluasi morfologi dan penyakit-penyakit ginjal. Ultrasonografi mulai banyak tersedia di fasilitas layanan kesehatan terutama pada daerah-daerah terpencil (Tuma et al., 2009).

Beberapa parameter pengukuran ginjal menunjukkan bahwa ukuran ginjal, ketebalan korteks ginjal dan echogenitas mempunyai hubungan dengan fungsi ginjal. Perubahan pada ketebalan korteks ginjal merupakan tanda penting pada penyakit ginjal dan telah digunakan sebagai indeks untuk mengevaluasi ginjal sehat. Penelitian sebelumnya oleh Beland et al., (2011) telah menunjukan bahwa pengukuran tebal parenkim ginjal dengan USG lebih akurat dibandingkan dengan pengukuran panjang aksis ginjal bila dihubungkan dengan laju filtrasi glomerulus. Demikian pula yang dilakukan oleh Yamashita et al., (2015) mengidentifikasi korelasi linier antara perkiraan laju filtrasi glomerulus dan ketebalan korteks ginjal.

Selain pemeriksaan USG untuk menilai morfologi ginjal, pemeriksaan Doppler juga dapat dilakukan walaupun memerlukan teknik dan resolusi yang baik. Pemeriksaan resistive index ginjal dapat menilai kelainan vaskular yang terjadi pada ginjal. Evaluasi pembuluh darah ginjal dapat memberikan informasi diagnosis dan prognosis pasien obstruksi untuk menentukan sifatnya reversible atau irreversible. Belum banyak penelitian yang mengkorelasikan antara pengukuran indeks resistif dan ketebalan korteks ginjal pada pasien dengan hidronefrosis (Kawai et al., 2011; Viazzi et al., 2014). Sonografi dupleks ginjal sangat sensitif dan spesifik untuk diagnosis uropati obstruktif. Peningkatan resistive index ginjal yang terhambat dapat menjadi alat 
diagnostik yang berguna dalam situasi di mana urografi intravena tidak dapat dilakukan atau dikontraindikasikan (Apoku et al., 2015). Penelitian yang telah dilakukan bertujuan untuk mengetahui korelasi ketebalan korteks ginjal dan resistive index ginjal berdasarkan pemeriksaan USG pada pasien hidronefrosis.

\section{METODE PENELITIAN}

Penelitian dilakukan dengan menggunakan metode observasional dengan rancangan potong lintang. Penelitian dilakukan di Bagian Radiologi Rumah Sakit Umum Pusat Dr. Wahidin Sudirohusdo Makassar pada bulan Mei-Agustus 2019. Variabel penelitian terdiri dari variabel bebas berupa ketebalan korteks ginjal dengan satuan centimeter $(\mathrm{cm})$ dan resistive index, serta variable tergantung hidronefrosis (berdasarkan SFU grading system). Populasi penelitian merupakan pasien hidronefrosis yang dirujuk dari bagian instalasi rawat jalan maupun rawat inap untuk melakukan pemeriksaan USG abdomen ke bagian instalasi Radiologi RSUP Dr. Wahidin Sudirohusodo, dengan kriteria eksklusi yaitu pasien hidronefrosis yang tidak memungkinkan untuk dilakukan pemeriksaan usg ginjal. Penelitian ini telah mendapat persetujuan etik dari Komite Etik Penelitian Kesehatan RSUP Dr.Wahidin Sudirohusodo Makassar, Fakultas Kedokteran Universitas Hasanuddin dengan Nomor: 444/H4.8.4.5.31/PP36-KOMETIK/2018.

Pasien yang memenuhi kriteria inklusi diberikan penjelasan lengkap mengenai penelitian. Pasien yang bersedia mengikuti penelitian mengisi dan menandatangani informed consent. Selanjutnya pasien menjalani pemeriksaan USG ginjal dengan mengggunakan transduser konveks frekuensi 3.5-5 Mhz dengan posisi supine atau lateral decubitus. Namun, jika kontur ginjal terhalang udara saluran cerna, maka dilakukan scan longitudinal mengikuti akses ginjal. USG ginjal dilakukan untuk menentukan derajat hidronefrosis untuk masing-masing ginjal, kemudian dilakukan pengukuran tebal korteks yang diukur dari puncak medulla pyramid tegak lurus kearah kapsul ginjal. Pengukuran dilakukan sebanyak 3 kali, diambil rata-rata dan dianyatakan dalam satuan centimeter, selanjutnya pengukuran resistive index (RI) dilakukan pada level arteri arcuate atau interlobar yang berdekatan dengan medulla pyramids. Pengukuran dilakukan pada beberapa bagian yang berbeda (superior, median dan lower). RRI dihitung dengan rumus: (peak systolic velocity-end diastolic velocity)/peak systolic velocity, dan diambil rata-rata dari 3 tempat pengukuran untuk masing-masing ginjal (Hansen, 2015). Analisis data dan hasilnya disajikan dalam bentuk tabel.

Semua data yang diperoleh dicatat dalam formulir data penelitian, kemudian dikelompokkan berdasarkan tujuan dan jenis data. Selanjutnya data akan diolah menurut metode statistik Spearman. Pengolahan data statistik berdasarkan uji korelasi menggunakan Software Statistical Programme Social Science (SPSS versi 21).

\section{HASIL DAN PEMBAHASAN}

Selama periode penelitian didapatkan jumlah responden sebanyak 40 pasien yang terdiri dari 17 laki-laki dan 23 perempuan dengan karakteristik seperti yang tercantum pada Tabel I. Pemeriksaan pengukuran ketebalan korteks ginjal dapat dilihat pada Gambar 1. 
Tabel I. Distribusi sampel berdasarkan demografi

\begin{tabular}{llll}
\hline Demografi & & $\mathbf{N}$ & $\mathbf{\%}$ \\
\hline Jenis & Laki-laki & 17 & 42,5 \\
Kelamin & Perempuan & 23 & 57,5 \\
\hline \multirow{3}{*}{ Umur } & $20-30$ & 4 & 10 \\
(tahun) & $31-40$ & 5 & 12,5 \\
& $41-50$ & 14 & 35 \\
& $51-60$ & 13 & 32,5 \\
\hline
\end{tabular}

Sumber: Data primer terolah

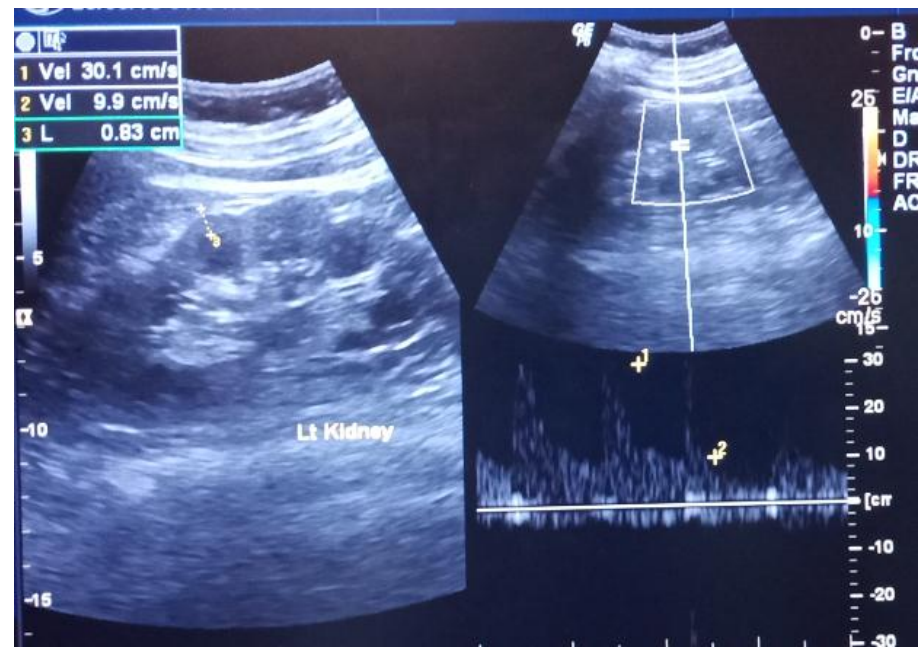

Gambar 1. Hasil pemeriksaan USG ginjal

Gambar 1 menunjukkan pemeriksaan pengukuran ketebalan korteks ginjal yang diukur dari puncak medulla pyramid tegak lurus ke arah kapsul ginjal dan pengukuran RI pada level arteri arcuata atau interlobar yang berdekatan dengan medulla pyramids. Distribusi derajat hidronefrosis dapat dilihat pada Tabel II.

Tabel II. Distribusi responden berdasarkan derajat hidronefrosis ginjal kanan dan kiri

\begin{tabular}{llll}
\hline Derajat hidronefrosis & $\mathbf{n}$ & $\mathbf{\%}$ \\
\hline Ginjal Kanan & Berat & 11 & 27,5 \\
& Sedang & 8 & 20 \\
& Ringan & 21 & 52,5 \\
\hline Ginjal Kiri & Berat & 8 & 20 \\
& Sedang & 10 & 25 \\
& Ringan & 22 & 55 \\
\hline
\end{tabular}

Sumber : Data primer terolah 
Tabel II menunjukkan bahwa derajat hidronefrosis paling banyak didapatkan pada derajat ringan $(52,5 \%)$ pada ginjal kanan dan $(55 \%)$ pada ginjal kiri. Rentang ketebalan korteks dan resistive index terdapat pada Tabel III.

Tabel III. Hasil pengukuran ketebalan korteks dan resisitive index

\begin{tabular}{lcccc}
\hline USG Dupleks Ginjal & Min & Maks & Mean & SD \\
\hline Ketebalan korteks (cm) & & & & \\
Ginjal Kanan & 0,26 & 1,79 & 0,90 & 0,34 \\
Ginjal Kiri & 0,22 & 1,57 & 0,84 & 0,27 \\
\hline Resistive Index & & & & \\
Ginjal kanan & 0,51 & 0,81 & 0,68 & 0,07 \\
Ginjal Kiri & 0,52 & 0,95 & 0,77 & 0,09 \\
\hline
\end{tabular}

Sumber : Data primer terolah

Tabel III menunjukkan bahwa rentang ketebalan korteks ginjal kanan yaitu 0,26-1,79 cm dengan nilai rerata $0,90 \mathrm{~cm}$ dan ketebalan korteks ginjal kiri yaitu $0,22-1,57 \mathrm{~cm}$ dengan nilai rerata $0,84 \mathrm{~cm}$. Rentang resistive index ginjal kanan yaitu 0,51-0,81 dengan nilai rerata 0,68 dan rentang resisitive index ginjal kiri yaitu 0,52-0,95 dengan nilai rerata 0,77.

Tabel IV menunjukkan hasil uji korelasi Spearman yaitu didapatkan koefisien korelasi pada ginjal kanan $(\mathrm{r}=-0,804$ dan $p=0,0001)$ dan ginjal kiri $(\mathrm{r}=-0,797$ dan $p=0,0001)$. Terdapat korelasi bermakna dengan arah korelasi negatif dengan kekuatan korelasi kuat. Semakin berat derajat hidronefrosis maka semakin berkurang ketebalan korteks ginjal.

Tabel IV. Korelasi antara ketebalan korteks ginjal dengan derajat hidronefrosis

\begin{tabular}{lll}
\hline Derajat Hidronefrosis & \multicolumn{2}{l}{ Ketebalan Korteks Ginjal } \\
\cline { 2 - 3 } & $\mathbf{r}$ & $\boldsymbol{p}$ \\
\hline Ginjal Kanan & $-0,804$ & 0,0001 \\
Ginjal kiri & $-0,797$ & 0,0001 \\
\hline
\end{tabular}

Keterangan : $r=$ koefisien korelasi negatif; $p=$ value

Hasil uji korelasi Spearman (Tabel V) menunjukkan koefisien korelasi ginjal kanan sebesar $(\mathrm{r}=0,310$ dan $p=0,052)$ dan ginjal kiri ( $\mathrm{r}=0,185$ dan $p=0,254)$, maka dapat disimpulkan bahwa tidak ada korelasi yang bermakna antara derajat hidronefrosis dengan resistive index.

Tabel V. Korelasi antara resistive index ginjal dengan derajat hidronefrosis

\begin{tabular}{lll}
\hline Derajat Hidronefrosis & \multicolumn{2}{l}{ Resistive Index Ginjal } \\
\cline { 2 - 3 } & $\mathbf{r}$ & $\boldsymbol{p}$ \\
\hline Ginjal Kanan & 0,310 & 0,052 \\
Ginjal kiri & 0,185 & 0,254 \\
\hline
\end{tabular}

Keterangan $: r=$ koefisien korelasi $; p=$ value 
Tabel VI menunjukkan hasil uji korelasi Pearson yaitu koefisien korelasi ginjal kanan sebesar $(\mathrm{r}=-0,057$ dan $p=0,728)$ dan ginjal kiri $(\mathrm{r}=-0,240$ dan $p=0,135)$, maka dapat disimpulkan bahwa tidak ada korelasi yang bermakna antara ketebalan korteks dengan resistive indeks pada pasien dengan hidronefosis.

Tabel VI. Korelasi antara ketebalan korteks dengan resistive index ginjal kanan dan kiri

\begin{tabular}{lll}
\hline Ketebalan Korteks Ginjal & \multicolumn{2}{l}{ Resistive Index Ginjal } \\
\cline { 2 - 3 } & $\mathbf{r}$ & $\boldsymbol{p}$ \\
\hline Ginjal Kanan & $-0,057$ & 0,728 \\
Ginjal kiri & $-0,240$ & 0,135 \\
\hline
\end{tabular}

Keterangan : $r=$ koefisien korelasi $; p=$ value

Selama periode penelitian didapatkan jumlah sampel sebanyak 40 pasien. Pasien hidronefrosis pada penelitian ini lebih banyak perempuan yang berumur diatas 20 tahun dengan subyek penelitian terbanyak berada pada kelompok umur 41-50 tahun. Hasil penelitian menunjukkan korelasi yang bermakna antara derajat hidronefrosis dengan ketebalan korteks ginjal kanan dan kiri, dengan arah korelasi negatif $(p=0,0001)$, semakin tinggi derajat hidronefrosis semakin tipis korteks ginjal.

Hidronefrosis merupakan suatu kondisi klinis umum sebagai distensi dari calyces ginjal dan pelvis oleh urin sebagai akibat dari obstruksi aliran keluar urin ke distal dari pelvis renalis. Hidronefrosis dinilai berdasarakan Society of Fetal Urology (SFU) Grading System, yaitu ringan, sedang dan berat (Kim, 2013; Häggström, 2017, Braga 2018). Rerata responden penelitian pada ginjal kanan menunjukkan bahwa 21 pasien $(52,5 \%)$ mengalami hidronefrosis derajat ringan, 8 pasien $(20 \%)$ derajat sedang, dan 11 pasien $(27,5 \%)$ derajat berat, sedangkan pada ginjal kiri menunjukkan 22 pasien $(55 \%)$ derajat ringan, 10 pasien $(25 \%)$ derajat sedang dan 8 pasien (20\%) derajat berat. Berdasarkan penelitian ini hampir 11\% tidak menunjukkan hidronefrosis dan mayoritas (71\%) menunjukkan hidronefrosis ringan. dengan penyebab paling umum kedua ginjal adalah urolithiaisis. Hasil ini sesuai dengan penelitian sebelumnya yang dilakukan oleh Alshoabi SA (2018) bahwa batu ginjal dan ureter penyebab hidronefrosis yang paling umum. Hasil ini konsisten dengan penelitian sebelumnya oleh Abdelmaboud SO et al. (2015), yang melaporkan bahwa batu ginjal dan ureter adalah penyebab hidronefrosis pada 54\% pasien dewasa. Penelitian sebelumnya oleh Hall (2009) dan Nuraj et al., (2017), yang melaporkan bahwa batu ginjal pada laki-laki hampir dua kali lipat dibanding perempuan. Distribusi karakteristik responden pada penelitian ini adalah 42,5\% laki-laki dan 57,5\% perempuan. Hal ini mungkin disebabkan karena jumlah sampel yang tidak berimbang dalam penelitian ini antara laki-laki dan perempuan.

Hidronefrosis dapat terjadi akibat proses anatomi atau fungsional yang mengganggu aliran urin. Gangguan ini dapat terjadi di mana saja di sepanjang saluran kemih dari ginjal ke meatus uretra. Peningkatan tekanan ureter menyebabkan perubahan yang ditandai dalam filtrasi glomerulus (GFR), fungsi tubular, dan aliran darah ginjal. Tingkat GFR menurun secara signifikan dalam beberapa jam setelah obstruksi akut. Penurunan GFR yang signifikan ini dapat bertahan selama berminggu-minggu setelah pemulihan obstruksi. Selain itu, kemampuan tubulus ginjal untuk mengangkut natrium, kalium, dan proton, berkonsentrasi dan untuk mengencerkan urin sangat terganggu (Panagiotis et al.,2014; Sja'bani, 2014). 
Ketebalan korteks normal berkisar 0,8-1,2 cm. Rentang rerata tebal korteks ginjal kanan pada penelitian ini yaitu $0,26-1,79 \mathrm{~cm}$ dengan rerata $0,90 \mathrm{~cm}$, dan ginjal kiri yaitu $0,22-1,57 \mathrm{~cm}$ dengan rerata 0,84 cm. Nitzsche et al., (1993) mengananalisis 142 ginjal yang hidronefrosis dan menemukan bahwa kurang dari 10\% memiliki fungsi kurang dari 40\%, dengan korteks yang atrofi. Beland et al., (2011), menyatakan bahwa ketebalan korteks ginjal yang di ukur dengan USG merupakan prediktor terhadap fungsi ginjal. Pemeriksaan ketebalan korteks ginjal dengan USG dapat memberi informasi prognostik serta perawatan lanjut terhadap penderita penyakit ginjal kronik (Mehmet et al., 2018). Penyakit ginjal kronik telah terdiagnosis pada sekitar 10\% populasi.

Hasil uji statistik Spearman didapatkan hasil korelasi yang tidak signifikan antara derajat hidronefrosis dengan RI $(p=0,052)$ ginjal kanan dan $(p=0,254)$ ginjal kiri, namun terdapat kecenderungan semakin meningkatnya nilai rerata RI terhadap derajat hidronefrosis. Hal tersebut ditunjukkan dengan nilai pada ginjal kanan derajat ringan $(0,66)$, sedang $(0,70)$, berat $(0,72)$ sedangkan ginjal kiri yaitu derajat ringan $(0,77)$, sedang $(0,79)$ dan berat $(0,81)$. Hal ini berarti bahwa hemodinamik arteri ginjal berubah sebagai respon terhadap obstruksi saluran kemih. Terjadinya obstruksi saluran kemih menyebabkan peningkatan resistensi renovaskular. Peningkatan resistensi pembuluh darah intrarenal mengurangi kecepatan aliran darah diastolik sehingga menyebabkan RI meningkat. Resistive index mempunyai korelasi dengan kelainan tubulointerstitial dan vaskular. Dengan adanya peningkatan RI pada penyakit ginjal kronis (PGK) berhubungan dengan berat dan luasnya perubahan jaringan seperti tubulointerstitial fibrosis dan arteriosclerosis. Semakin luas kerusakan jaringan maka RI akan semakin meningkat.

Peningkatan nilai RI pada penelitian ini tampak pada responden dengan urolithiasis disertai hipertensi maupun diabetes mellitus pada kelompok umur 41-50 tahun yang merupakan responden terbanyak pada penelitian. Namun, rata-rata responden telah menjalani pembebasan obstruksi melalui terapi obat non steroid maupun melalui pemasangan DJ stent, dengan durasi obstruksi yang beragam lebih dari sebulan dengan tingkat obstruksi dan derajat hidronefrosis yang berbeda antara ginjal kanan dan kiri disertai gejala nyeri yang intermiten.

Pada penelitian ini juga dilakukan uji statistik untuk menilai korelasi ketebalan korteks dan RI ginjal kanan dan kiri. Hasil uji statistik Pearson menunjukkan korelasi yang tidak bermakna antara ketebalan korteks dan RI ginjal kanan $(\mathrm{p}=0,728)$ dan ginjal kiri $(\mathrm{p}=0,135)$. Ginjal dengan obstruksi berat ditandai dengan adanya hidronefrosis tidak menunjukkan peningkatan RI. Rendahnya respon diyakini akibat penurunan aliran darah pada obstruksi kronis dan penurunan tekanan filtrasi korteks ginjal yang berfungsi minimal atau sistem pengumpul yang mengalami dilatasi. Ginjal yang mengalami obstruksi ringan maupun sedang didapatkan nilai rerata RI meningkat sesuai dengan beratnya hidronefrosis.

Berdasarkan pemeriksaan ultrasonografi menunjukkan tidak terdapat korelasi antara ketebalan korteks dan RI ginjal. Peneliti menyarankan agar ukuran ketebalan korteks ginjal pada pemeriksaan USG perlu dilaporkan khususnya pada pasien uropati obstruksi dengan hidronefrosis. Lebih dari itu, perlu dilakukan penelitian dengan jumlah sampel pada pasien uropati obstruksi yang lebih banyak dan terbagi secara merata pada setiap kelompok grading, sehingga dapat diketahui nilai cut off rerata RI. 


\section{KESIMPULAN}

Terdapat korelasi yang bermakna antara derajat hidronefrosis dengan ketebalan korteks ginjal, dengan arah korelasi negatif. Semakin tinggi derajat hidronefrosis semakin tipis korteks ginjal. Terdapat kecenderungan peningkatan derajat hidronefrosis juga meningkatkan nilai resistive index ginjal, meskipun secara statistik tidak bermakna.

\section{UCAPAN TERIMA KASIH}

Ucapan terima kasih kepada seluruh pimpinan, staf dan teman-teman PPDS Departemen Radiologi Fakultas Kedokteran Universitas Hasanudin dan Rumah Sakit Dr. Wahidin Sudirohusodo, Makassar atas arahan, bimbingan dan bantuan yang diberikan mulai dari penulisan sampai dengan selesainya karya akhir ini.

\section{DAFTAR PUSTAKA}

Alshoabi, A.S. 2018. Association between grades of hydronephrosis and detection of urinary stones by ultrasound imaging. Pakistan Journal of medical science 34(4): 955-958.

Abdelmaboud, O.S., Gameraddin, B.M., Ibrahim, T., Alsayed, A. 2015. Sonographic evaluation of hydronephrosis and determination of the main causes among adults. International Journal of Medical imaging 3(1): 1-5.

Apoku, I.N., Ayoola, O.O., Salako, A.A., Idowu, B.M. 2015. Ultrasound evaluation of obstructive uropathy and its hemodynamic responses in southwest Nigeria. International Braz J Urol 41(3): 556-561.

Braga, L.H., McGrath, M., Farrokhyar, F., Jegatheeswaran, K., Lorenzo, A.J. 2018. Society for fetal urology classification vs urinary tract dilation grading system for prognostication in prenatal hydronephrosis: a time to resolution analysis. American urology association journals 199(6): 1615-1621.

Beland, M.D., Walle, N.L., Machan, J.T., Cronan, J,J., 2010. Renal cortical thickness measured at ultrasound : is it better than renal length as in indicator of renal function in chronic kidney disease?. American Journal Roentgenology 195:146-149.

Esprit, D.H., Koratala, A., Chornyy, V., Wingo, C.S. 2017. Obstructive nephropathy without hydronephrosis: Suspicion is the key. Urology 101: 9-10.

Häggström, M. 2017. Ultrasonography of hydronephrosis. Radlines https://radlines.org/Ultrasonography_of_hydronephrosis. Diunduh Maret 2018

Hall, P.M. 2009. Nephrolithiasis: treatment, causes, and prevention. Cleve Clin J Med 76(10): 583-591.

Hansen, K.L., Nielsen, M.B., Ewertsen, C. 2016. Ultrasonography of the kidney: a pictorial review. Diagnostics (Basel) 6(1): 2-18 
Kawai, T., Kamide., Onishi, M., Yamamato-Hanasaki, H., Baba, Y., Hongyo, K., et al. 2011. Usefulness of the resistive index in renal doppler ultrasonography as an indicator of vascular damage in patients with risks of atherosclerosis. Nephrology Dialysis Transplantation 26(10) : 3256-3262.

Kim, S.Y., Kim, M.J. Yoon, C.S., Lee, M.S., Han, K.H., Lee, M.J. 2013. Comparison of the reliability of two hydronephrosis grading systems: the society for foetal urology grading system vs. the onen grading system. Clin Radiol 68(9): 484-490.

Lameire, N., Van Biesen, W., Vanholder, R. 2005. Acute renal failure. Lancet 365 (9457): 41730.

Mehmet, K., Bekir, A., Serkan, G., Mumtaz, Y. 2018. Clinical significance of renal cortical thickness in patients with chronic kidney disease. Ultrasonography 37(1): 50-54.

Nitzsche, E. U., Zimmerhackl, L. B., Hawkins, R., Stöver, B., Frankenschmidt, A, Sigmund, $\mathrm{G}$, et al. 1993. Correlation of ultrasound and renal scintigraphy in children with unilateral hydronephrosis in primary workup. Pediatr Nephrol 7(2): 138-42.

Nuraj, P., Nexhmi, H. 2017. The diagnosis of obstructive hydronephrosis with color doppler ultrasound. Acta Informatica Medica 25(3): 178-181.

Panagiotis, I., Mourmouris, Theodoros, C., Athanasios, G., Papatsoris. 2014. Obstructive Uropathy: from etiopathology to therapy. World Journal of Nephrology and Urology 3(1): 1-6.

Singh, Iqbal, Strandhoy Jack W, Assimos Dean G. 2012. Pathophysiology of urinary tract obstruction. Campbell-Walsh Urology 10th Edition, Chapter: Volume (II): 212-219.

Sja’bani, M. 2014. Batu saluran kemih. Buku Ajar Ilmu Penyakit Dalam Edisi VI. Interna Publishing: 2121-8.

Sukmagara, J., Danarto, H.R. 2015. Prognosis of obstructive nephropathy patients after percutaneus nephrostomy. Indonesian Journal of urology 22(1): 53-59.

Tuma, J., Trinkler, F., Zát’ura, F., Nováková, B. 2009. Genitourinary ultrasound. EFSUMBEuropean Course Book Available from: http://www.efsumb.org/ecb/ecb-ch09urogenital.pdf. Diunduh Maret 2018. 
Viazzi, F., Leoncini, G., Derchi, L.E., Pontremoli, R. 2014. Ultrasound Doppler renal resistive index: a useful tool for the management of the hypertensive patient. Journal of hypertension 32(1): 149-153.

Yamashita, S.R., Atzingen, A.C., Iared, W., Bezerra, A.S., Ammirati, A.L., Canziani, M.E., D'Ippolito, G. 2015. Value of renal cortical thickness as a predictor of renal function impairment in chronicrenal disease patients. Radiologia Brasileria 48(1): 12-16. 